\title{
Unexpected benefits of pre-university skills training for A-level students
}

${ }^{a}$ H.L. Jones ${ }^{\star}$ aE.H. Gaskell, bJ.R. Prendergast and ${ }^{\text {CA.D. Bavage }}$

a School of Biological Sciences, University of East Anglia, Norwich Research Park, Norwich, NR4 7TJ

bJRP Information Services, Lymington, Hants, SO41 OZP

c Wymondham High Academy Trust, Folly Road, Wymondham Norfolk. NR18 OQT

Running header of author names: Jones et al.

${ }^{*}$ Corresponding author

e-mail: harriet.jones@uea.ac.uk 


\section{Abstract}

First-year undergraduates can find the transition from the prescriptive learning environment at school to one of self-directed learning at university, a considerable challenge. A Pre-university Skills Course (PSC) was developed to address this issue by preparing sixth formers for the university learning style. It was piloted with students in the year prior to A-level examinations at a selective state-funded school in East Anglia. The present paper examines the effect of the course on the students' A-level tariff. Chi-squared analysis of A-level grades of students with comparable GCSE results, indicate that students who undertook the PSC performed significantly better in their A-level results than those who did not. These data demonstrate how skills training can improve A-level performance as well as assisting in the transition to university.

Key words

Transition, A-level, Skills, Pre-university, University 


\section{$\underline{\text { Introduction }}$}

Differences in teaching style between school and university mean that many new undergraduates face considerable challenges when making the transition (Fisher, Cavanagh, and Bowles 2011). It is often argued that school pupils are simply provided with the information they require to pass exams (Keane 2011) and consequently enter university with minimal experience of self-directed learning, with little facility for original or critical thought and with an inadequate grasp of their subject as a whole (King and Aves 2012). Despite some variation in emphasis, the skills undergraduates struggle with appear similar across all disciplines (Jones 2011).

To reduce the time and money that universities spend on 'catch up' modules, and to facilitate a shorter period of adjustment, a Pre-university Skills Course (PSC) was launched in January 2011 (www.preuniversityskills.com) which included an eight session course for school teachers to teach to their Year 12 and 13 students (lower and upper sixth form). Hundreds of teachers, nationally, and more recently internationally, have completed a CPD (Continuing Professional Development) course, to instruct them on how to deliver the material to their pupils. The course comprises eight practical workshops, covering aspects such as structuring writing, taking notes and referencing, to enable students to appreciate the level at which they will be expected to work at university. Until the launch of the PSC, there were no courses designed to be taught by school teachers in schools that targeted university preparedness across academic disciplines.

The PSC has been enthusiastically welcomed by teachers and students alike. It was not designed to assist with the A-level courses themselves, but anecdotally teachers reported improved ability levels in their students following the Course. There was, however, no empirical evidence for this. The current study examines the A-level grades of a cohort of sixth form students to explore whether there was any difference in the grades achieved as a result of students taking the PSC.

\section{Method}

In a selective, state-funded school in East Anglia, the A-level grades of 172 students were recorded. All students in the study had taken at least three A-level qualifications. The cohort was divided into two subsets: those that had completed the Pre-university Skills Course (PSC) $(n=17)$; and those who had not $(n=155)$.

The students described here were the first cohort in this school to take the full PSC; (an eight-session course for sixth form pupils, delivered by their teachers, who had received instruction from a CPD (Continuing Professional Development) training course in how to deliver it (www.preuniversityskills.com)). After the students had completed their AS examinations (the end of Year 12, lower sixth form) students 
were asked to volunteer to take part in the course. The ability range of those taking the PSC was representative of the ability and attitude across the whole cohort.

The PSC was taught to students during the six weeks between the end of study leave following the AS examinations and the end of the academic year. It was delivered over two days with lessons 1-5, dealing with scholarship in the Arts and Sciences, synthesising material, and referencing, on the first day, and lessons 6 and 7 , dealing with note-taking and essay structure, on the second day. Following lesson 7 students write an essay which they self- and peer- assessed in lesson 8 . Students were given one week to write the essay and lesson 8 was delivered following submission. The PSC was delivered using the full set of course materials specially developed for the purpose at UEA.

To determine the academic standard of students in each group prior to their A-level studies, the GCSE results of all students were examined. GCSE performance was calculated by allocating points for GCSE grades as follows: $A^{*}=8, A=7, B=6, C=$ $5, D=4, E=3, F=2, G=1, U$ (fail) $=0$. A mean points level was calculated for each student. To ensure the most equitable comparison between the two groups, the PSC group was refined as follows: to remove extreme outliers, the top and bottom scores were eliminated from the PSC group $(n=15)$. For those not taking the PSC, only those whose scores lay between the upper and lower scores of the PSC group $(n=96)$ were included in the next stage. The Mann-Whitney $U$ test was used to confirm that no significant difference existed between the mean GCSE score of these two groups $\left(U_{15,96}=576, p>0.05\right)$.

To test for differences between the A-level results of students who completed the PSC and those who did not the numbers of passes at $A^{*}$ to $E$ grade were counted for each student. The Chi squared test was used to compare counts for the PSC group with 1000 bootstrapped replicates of size $n=15$ from the group which did not take the Course.

\section{$\underline{\text { Results and Discussion }}$}

Students who participated in the PSC achieved significantly better results in their Alevels than those who did not. Whilst individual student motivation will undoubtedly play an influential role, these results show evidence of the value of the PSC. Not only is the course designed to ease many of the potential difficulties that students can experience during the school to university transition, it also seems to improve their chances of performing well at A-level and therefore being admitted to their university of choice in the first instance. Having received only eight lessons, students showed improved A-level tariff.

There was a significant difference in the final A-level tariffs between those who took the PSC and those who did not $(P<0.001)$; students who did not take the PSC extra 
course achieved the lower mean tariff of 308 points relative to 400 for those who took the PSU. With the bootstrap analysis the tariff score was significantly higher for those students who took the PSC $(P<0.05835 / 1000$ (Chi sqd $>12.592$, d.f. $=6))$ relative to those who did not.

By seeking to improve synoptic learning, researching, finding sources, essay-writing and referencing techniques, along with the wider skills of problem solving, analysis and critical thinking, the PSC may assist students at A-level as well as preparing them for higher education. Jansen \& Suhre (2010) have demonstrated that preuniversity preparation in study skills had a positive effect on students' progress at the undergraduate level. Here, the data demonstrates that such skills teaching also has a positive affect at school level.

Higton et al. (2012) have identified that an aptitude to learn in a way suitable for higher education is an extremely desirable quality in A-level students. By implementing study skills programs in schools, students are introduced to the learning styles which can help them throughout their academic life at school, university and beyond. Presently, with the widely held belief that A-levels are the best available measure with which to predict degree success (King \& Aves 2012), the benefits to students taking the PSC would seem to be both immediate and longterm. With this investigation limited to one selective state-funded school in East Anglia, further investigation would be highly desirable. However, here is clear evidence that helping students develop an appreciation of undergraduate-style learning skills can result in improved grades in A-level programmes. 


\section{References}

Fisher, R., J. Cavanagh, and A. Bowles. 2011. "Assisting transition to university: using assessment as a formative learning tool." Assessment \& Evaluation in Higher Education, 36 (2): 225-237. doi: 10.1080/02602930903308241

Higton, J., J. Noble, S. Pope, N. Boal, S. Ginnis, R. Donaldson, and H. Greevy. 2012. Fit for purpose?: the view of the higher education sector, teachers and employers on the suitability of $A$ levels. Ofqual commissioned report. Accessed October 22. http://dera.ioe.ac.uk/14104/1/2012-04-03-fit-for-purpose-a-levels.pdf Jansen, E. P., and C. J. Suhre. 2010. "The effect of secondary school study skills preparation on first-year university achievement." Educational Studies, 36 (5): 569580. doi: 10.1080/03055691003729070

Jones, H. 2011. "Are Our Students Prepared for University?" Bioscience Education, 18, doi: 10.3108/beej.18.3SE.

Keane, E. 2011. "Dependence-deconstruction: widening participation and traditionalentry students transitioning from school to higher education in Ireland." Teaching in Higher Education, 16 (6): 707-718.

King, N. C., and S. J. Aves. 2012. "Effect of A-level Subject Choice and Entry Tariff on Final Degree and Level 1 Performance in Biosciences." Bioscience Education, 